\title{
Vida pastoril en la precordillera andina (Guatin, San Pedro de Atacama, Chile)
}

George Serracino*, Rubén Stehberg L.**

\section{Introducción}

En la interpretación arqueológica, especialmente de pueblos agroalfareros tardíos, además del análisis, clasificación, tipificación y seriación de los artefactos, se debe recurrir a datos aportados por otras disciplinas. Una de ellas, la etnografía, proporciona importantes aportes a la interpretación cultural.

Creemos que para llegar a interpretar las colecciones del Museo de San Pedro de Atacama (Le Paige 1973: 9-20) es necesario estudiar un yacimiento en todos sus aspectos, enfocando el problema en un sentido ecosistémico.

Dentro de nuestro proyecto (Serracino et al. 1973: 41-42) hemos planificado un estudio etnográfico de la vida pastoril en la localidad de Guatin, el que nos dará luces sobre el aprovechamiento del medio ambiente del lugar y sus alrededores, explicando además el proceso del cambio cultural en la zona a través del tiempo.

El yacimiento de Guatin posee los parámetros para el estudio integral de la cultura atacameña, debido a la presencia de múltiples factores bióticos y abióticos en una isla de población típica dentro de la ecología del borde de la puna. La naturaleza geomorfológica de Guatin corresponde a una falla geológica en el sistema de levantamiento de la Cordillera de los Andes. La formación de la depresión de Guatin creó un reducto microambiental en el cual confluye el caudal de los ríos Puritama y Puripica. Estos ríos alimentan la localidad con una cantidad considerable de agua, a lo largo de todo el año. En el pasado, el caudal fue más cuantioso y produjo una formación de suelos con grava de más de $2 \mathrm{~m}$ de profundidad. En tiempos recientes se depositó una capa de arena eólica. Esta formación de suelos contrastantes con

\footnotetext{
* Museo Arqueología, San Pedro de Atacama, Chile.

** Sección Antropología, Museo Nacional de Historia Natural, Casilla 787, Santiago, Chile.
}

los alrededores inmediatos, de formación liparítica y basáltica, es la causa de los asentamientos humanos y de las variantes bióticas existentes en este reducto (el trabajo geomorfológico completo está en preparación).

Estos factores abióticos causaron el desarrollo de una población biótica de plantas, insectos, aves y animales. La descripción de ésta ha sido presentada en detalle, en trabajos ya citados, especialmente la descripción botánica que juega un papel importante en el desarrollo de la vida de animales y hombres. El asentamiento humano en Guatin ha sido parcialmente descrito, en lo que respecta a la época tardía, en uno de nuestros trabajos (Serracino y Stehberg 1974: 11-55). Pensamos que Guatin ofrece un desarrollo cultural desde los tiempos más tempranos hasta la actualidad (Le Paige 1958: 147; Serracino et al. 1973: 41-42). El presente informe trata de la ocupación actual de Guatin y abarca, muy sumariamente, un problema de gran validez que nos permitirá entender la utilización de la puna por los hombres, tanto en el pasado como en la actualidad.

El problema de la vida pastoril es de gran importancia para comprender el sistema de la tribu atacameña, para integrar el uso de la puna al sistema económico y social de la provincia de Antofagasta. La integración de esta vida a las actividades mineras y agrícolas es un sistema que otorga estabilidad a la economía regional. Sobre este punto no entraremos en mayores detalles en el presente artículo y nos limitaremos a describir uno de los sistemas de vida pastoril existentes en San Pedro de Atacama. Sin embargo, creemos útil señalar este factor como hecho indicativo de que un estudio etnográfico puede contribuir al desarrollo integral de una región.

La descripción, que se vierte en las páginas siguientes, es el primer paso para comenzar a entender lo que es pastoreo en el departamento de El Loa. La mera descripción trascenderá en el futuro cuando sean efectuados otros estudios. 


\section{Antecedentes históricos sobre vida pastoril}

El pastoreo ha sido, desde épocas muy tempranas, una de las actividades de sustento en toda la zona andina. Muchas veces esta actividad ha sido combinada con la horticultura, pero la base principal la constituye el ganado, especialmente en la zona de la puna, en alturas sobre $3000 \mathrm{~m}$. snm. En el mundo en general, fuera de pocas excepciones, los antropólogos no se han dedicado a estudiar a los pastores como un sistema de vida económico, social o cultural. Sólo en los últimos años comienzan a aparecer trabajos sobre los sistemas de pastoreo. Un ejemplo de estos estudios son los de Irons y Dyson-Hudson (Eds.) Perspectives on nomadism Brill, Leiden (1972). Sin embargo, esta colección de trabajos no trata de los Andes.

En la historia encontramos algunos estudios acerca de la importancia de los pastores en los Andes, en tiempos pasados, especialmente en el período incásico. Sobre este aspecto Murra (1968: 115-151, 1972: 429-476 y sgtes.) ha escrito sobre el papel que los pastores desempeñan en el sistema económico-social precolonial, especialmente en lo relativo a los incas y Lupakas de los Andes Centrales. La importancia del pastoreo dentro del sistema indígena ha sido que poseían habilidad para manipular sistemas sociales convenientes a su medio ambiente.

La transhumancia no ha sido la única actividad de 1a cultura atacameña en el pasado y menos hoy día; recordemos que la crónica de Bibar (1958: 118) menciona la riqueza de siembra y de alimentos existentes en San Pedro de Atacama en el siglo XVI. En los alrededores del pueblo se encuentran los pastores hoy día y, aparentemente, su número fue mayor en el pasado. A este respecto dice Murra (1968: 121) refiriéndose a los Lupakas:

"Those areas not reached in a day by walking or ever seasonal migration, were settled by groups of colonist (the group can be as small as a single household) who herded, gathered, salt, grew tropical peppers or coca leaves".

Guatin, a $25 \mathrm{~km}$ al noreste de San Pedro de Atacama, presenta actualmente el caso de una sola familia con sus tropas (Figura 1), mientras que Machuca, a 70 $\mathrm{km}$, es un pueblito de 13 familias, y entre Machuca y Guatin, a $42 \mathrm{~km}$ de San Pedro, encontramos la localidad de Turipite que posee siete familias. San Pedro de Atacama mismo consta de 1100 personas y es netamente agrícola, mientras que las demás son eminentemente pastoriles, pero todas ellas se consideran de Atacama. Esto indicaría la existencia de un sistema en que un centro agrícola abarcaría también otras zonas dedicadas al pastoreo.

Por faltar el estudio de Machuca y Turipite no podremos incluirlos en este trabajo, sin embargo deben ser tomados en consideración si se quiere llevar adelante un estudio sistemático sobre el pastoreo. Por la carencia de documentos y estudios sobre el pastoreo entre los atacameños durante los períodos prehispánico y colonial, no podemos desarrollar un estudio histórico. Los primeros y escasos datos sobre el tema pueden extraerse de Boman (1908: 714), quien señala que el mantenimiento de las tropas de llamas estaba basado en la comida de los frutos del algarrobo (Prosopis silisquastrum, DC.), y en el ichu. En la descripción de Susques el autor dará bastantes indicadores de la vida social, cultural y económica. Interesante es la nota de Boman sobre la causa de la desaparición de los bosques de algarrobo y chañar (Geofrea decorticans), debido al desarrollo de la actividad minera y al uso excesivo de los árboles como combustible en los centros mineros, ocurrida hacia fines del siglo pasado. Boman (1908: 714) nota que los bosques descritos por Frezier (1716: 131) ya no existían más en su época.

Descripciones más detalladas pueden encontrarse en Bowman (1924: 339) donde concluye que "Development of the pasture land is the only known way of increasing the population and production". Bowman prosigue con un análisis minucioso sobre la validez económica del pastoreo en la puna, que merecería un análisis más detallado del que podemos realizar en este artículo. Es lamentable que Bowman haya sido el último hasta hace pocos años en escribir sobre esta materia. Esto explica, por lo tanto, el porqué nosotros sentimos la necesidad de tornar el estudio de todo un sistema de talaje en la provincia de Antofagasta. Valdrá la pena observar que las otras actividades del hombre, agricultura y minería, han surgido y murieron en el devenir de los tiempos, y sin embargo, el pastoreo, una forma primitiva de vivir, sigue siendo una actividad fundamental en los atacameños.

Este papel importante de los pastores en los Andes ha sido básico en estudios recientemente publicados de trabajos relativos al Perú (Flores Ochoa 1968; Browman 1974: 186-196). Este último intenta dar 


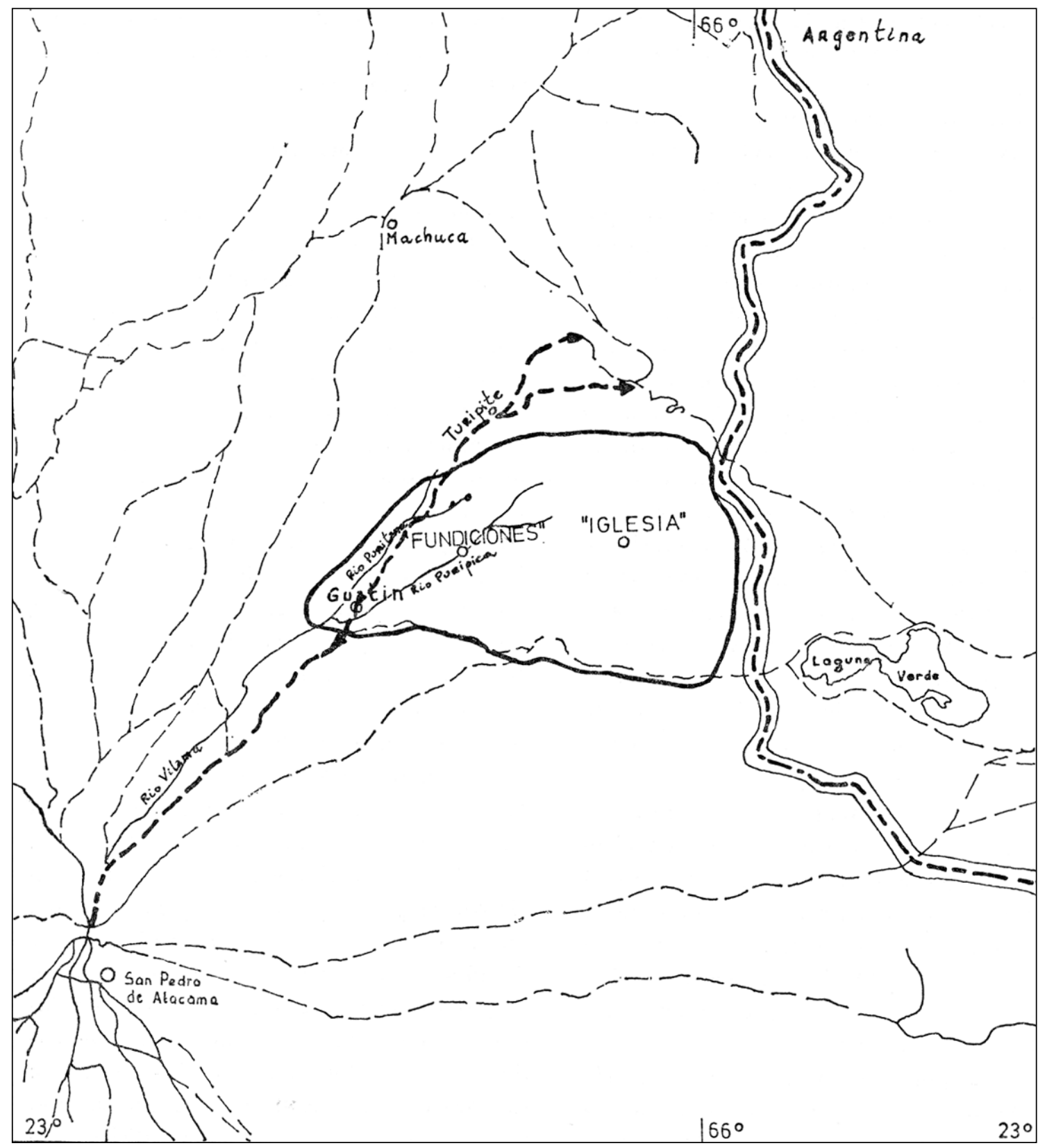

Figura 1. Zona de pastoreo tradicionalmente asignada a la familia Vilca. Se indican las estancias "FUNDICIONES" e "IGLESIAS" (Reproducción parcial de la Carta preliminar Chuquicamata - 2269 y Zapaleri - 2268, del Instituto Geográfico Militar, 1970. Escala 1:250.000).

un modelo del pastoreo en los Andes Centrales y Meridionales de Perú en un enfoque arqueológico, etnohistórico y etnológico.

Desde el punto de vista ecológico, valdría la pena ver la descripción de los varios nichos ecológicos que describe Clustard (1973) para la puna. El aprovechamiento máximo de estos nichos es el que genera la posibilidad de desarrollar la vida pastoril de los Andes. El pastor de Guatin logra mantener sus rebaños sanos y numerosos justamente porque aprovecha estos nichos ecológicos. En el control o uso de los varios nichos se parte siempre desde un centro y se viaja desde éste hacia los otros solamente por temporadas o días. Nuestro estudio se concentra sobre la actividad desarrollada desde el centro. Este 
trabajo deberá ser complementado con observaciones geográficas, botánicas y zoológicas en los otros lugares que los pastores denominan "estancias".

\section{Metodología}

Aunque no consideramos en nuestro plan arqueológico inicial estudiar la etnografía del lugar, el encontrar dos pastores de avanzada edad en la localidad y algunas circunstancias que facilitaron su observación nos hizo modificarlo a incluir también los aspectos etnográficos. La validez de esto ha sido señalada anteriormente en este trabajo: en primer lugar, de los escasos datos etnográficos sobre el Departamento de El Loa, señalados anteriormente, ninguno incluye Guatin; en segundo lugar, los trabajos etnológicos tienen valor en la interpretación arqueológica y, en tercer lugar, los datos etnográficos, aun los meramente descriptivos, poseen significación para otros científicos como los ecólogos, ecónomos, antropólogos sociales, botánicos, etc.

Guatin es un yacimiento arqueológico señalado por Le Paige (1959 y 1964) que no había sido estudiado. En nuestra visita al lugar el año 1972 se consideró la posibilidad de vivir con el pastor Juan Vilca y su ayudante, únicos habitantes de la localidad. Una vez llegados al lugar, en vez de levantar nuestro propio campamento decidimos vivir en las mismas condiciones de Juan Vilca, compartiendo su casa, dormitorios, cocina e inclusive su propia comida, a lo que el pastor accedió amablemente. Nuestra estada en dicha localidad tenía una duración de 15 días y se ha repetido durante los años a razón de un par de veces al año. En varias oportunidades realizamos excursiones a los alrededores de Guatin guiados por Vilca, quien nos explicó el sistema de pastoreo. El resto de su conocimiento nos fue transmitido en conversaciones diarias durante y después de las comidas. Uno de nosotros, que vivía en San Pedro de Atacama durante todo el año, pudo encontrar varias veces al pastor en dicha localidad y conversar más con él, como también averiguar mayores datos sobre su persona a través del contacto con aquellos habitantes de San Pedro que lo conocían. Lo que presentamos en este trabajo es el fruto de esas estadías en Guatin y de las conversaciones que sostuvimos con él.

Por los mismos motivos que dieron origen a este trabajo no lo podemos considerar realmente como uno etnográfico completo ya que, como se ha señalado, no hemos seguido a Vilca en su vida completa. Por esta razón no nos atribuiremos ni encasillaremos en un modelo etnográfico determinado o en cualquier enfoque técnico; sin embargo, señalaremos, en las partes pertinentes, lo que pensamos al respecto de una variante de hechos. Creemos que los datos descriptivos de este trabajo serán de utilidad para los investigadores correspondientes, quienes podrán ampliar el tema.

El orden del trabajo es el siguiente: descripción de la vivienda y tipos de campos de cultivos y corral, arquitectura, inventario de la casa, la biografía de Vilca, modo de vida, los trabajos diarios, relaciones sociales y la vida cultural y espiritual.

Queremos agradecer a Juan Vilca, quien nos dio alojamiento en su casa, nos enseñó su modo de vivir y su filosofia de vida, permitiéndonos la publicación de éste. A la señora Gloria Liberman quien nos acompañó en todos nuestros trabajos e inclusive nos ayudó al ordenamiento y redacción de las notas de campo, que hubieron de hacerse en el lugar mismo, en las noches y sin mayor iluminación que la luz de una vela. Al padre Gustavo Le Paige, quien nos visitó reiteradas veces durante nuestra estada en el lugar y con quien sostuviéramos discusiones sobre la vida pastoril en la zona. A todas aquellas personas que nos han brindado su ayuda indicándonos bibliografía y opiniones sobre el tema en cuestión.

\section{Vivienda, corrales y campos de cultivo (Figuras 2 y 3)}

Vivienda. Consta de cocina, bodega y dos cuartos edificados en 1935. En 1940 se agrega una pieza para visitas y un gallinero.

En la construcción de los muros se han utilizado piedras canteadas unidas con argamasa (de barro). Alcanzan una altura máxima de $2 \mathrm{~m}$ y se componen de 11 líneas superpuestas de piedras que varían entre los 18 y $34 \mathrm{~cm}$ de longitud. El techo posee tijerales de chañar y cardón, recubiertas con cortadera (cola de zorro) traída del río. Como alero del techo posee lajas de $33 \mathrm{~cm}$ de ancho y 7 de alto.

Cocina. Posee tres paredes, quedando abierta hacia el sur y permitiendo así visibilidad al camino que va a San Pedro de Atacama y al corral. En el centro, un par de fierros apoyados sobre dos piedras rectangulares constituyen el fogón. Al fondo hay un estante de madera y un mesón, este último de piedra incluido en la construcción de la pared. 


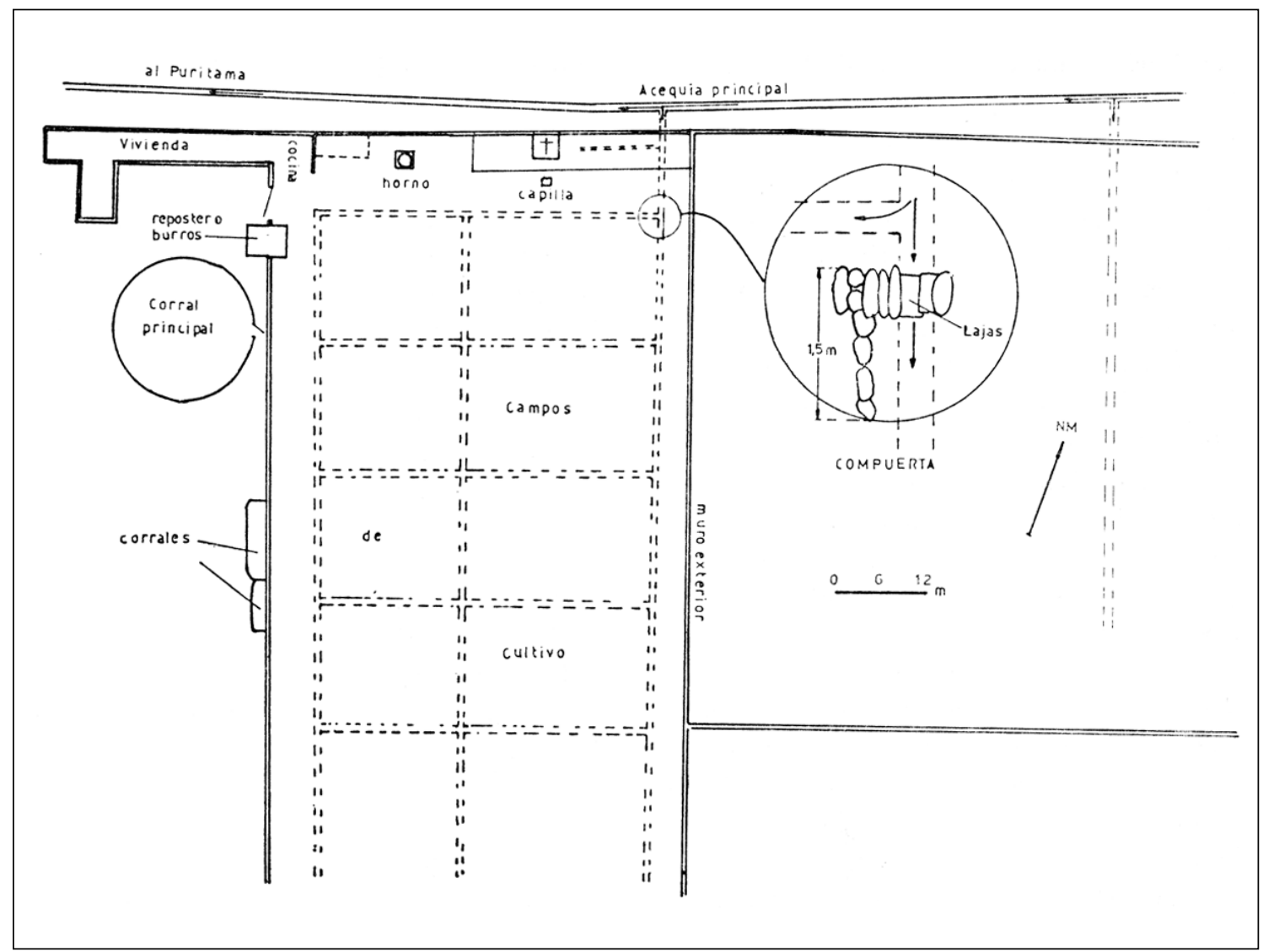

Figura 2. Croquis de ubicación de vivienda, corral y campos de cultivos.

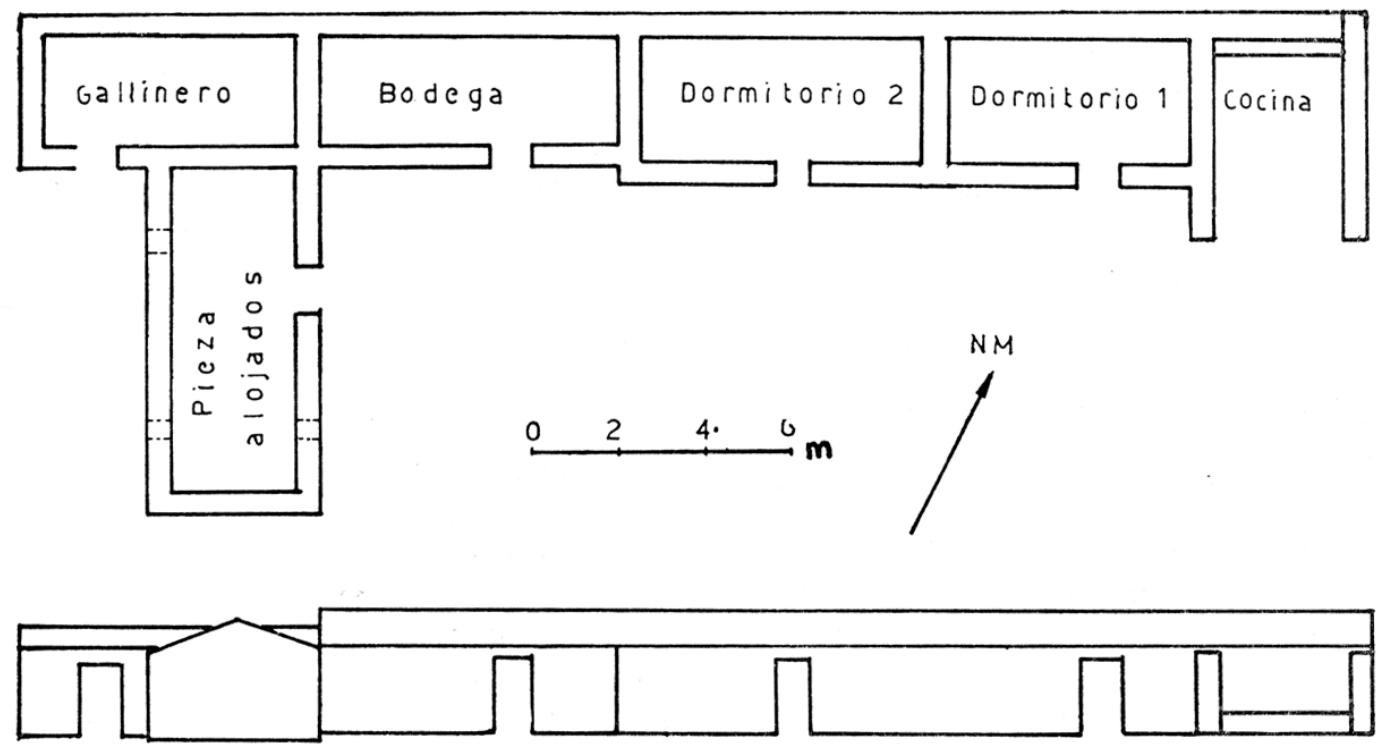

Figura 3. Planta y elevación de la vivienda. Se indica la funcionalidad de las piezas. 
Completan los muebles de cocina, una mesa grande de madera amarrada con tiras de cuero, tres banquetas y una silla. La vajilla de cocina se compone de 8 tazas de fierro enlozado, cuatro ollas grandes y medianas, cuatro sartenes (dos grandes y dos chicas), dos teteras (una para el agua y otra chica para el té), dos lavatorios, un jarro para agua, dos baldes, un embudo, un abridor de tarros, una piedra para moler pimienta y comino, un alambre para sacar las sopaipillas de la sartén, cinco platos, una escoba, una artesa grande, un trapo para secar vajilla colgado a la pared, tarro de Nescafé con orégano, comino y pimienta, un azucarero, un tarro para té, un colador, dos vasos de vidrio, dos cuchillos, siete cucharas, detergente (Omo), dos escobillas plásticas y una cocinilla en desuso.

Frente a la cocina, bajo un techo de zinc, se han instalado una mesa mediana, dos banquetas, con una función doble, comedor para visitas y mesa para trabajos manuales (confección de ojotas, etc.).

Dormitorio 1. Dormitorio ubicado al lado oeste de la cocina. Dos rectángulos de piedra rellenos con tierra, de $50 \mathrm{~m}$ de alto y adosados a la muralla, sobre el cual se depositan cueros, constituye la cama. Construido para una persona, era ampliado con madera de cardón para que cupiera la mujer.

Dormitorio 2. Posee un camarote de fierro y tres catres. Fue ocupado por los hijos de Juan Vilca.

Bodega. Despensa. En su interior se guardan principalmente los productos que distribuye la ECA (Empresa de Comercio Agrícola) de San Pedro de Atacama. Se maneja siempre con llave.

Pieza para alojados. Contiene en su interior una mesa grande de $1.85 \times 1.95 \mathrm{~m}$ y tres banquetas. Es el único cuarto con ventanas.

Gallinero. Originalmente construido como gallinero nunca fue utilizado como tal.

\section{Otras construcciones}

Corral principal. Posee forma circular, tamaño grande, se ubica al costado sur de la casa y es visible desde todas las piezas, especialmente desde la cocina. El muro está constituido por seis líneas superpuestas de piedras trabajadas, de un ancho máximo de 60 $\mathrm{cm}$ y 1.10 a $1.30 \mathrm{~m}$ de alto, cementadas con escasa argamasa.
Posee una puerta de acceso, por el costado este, de $1.14 \mathrm{~m}$ de alto y $1.90 \mathrm{~m}$ de ancho, constituida por dos palos verticales de cacto de $1.75 \mathrm{~m}$ de alto, atravesadas por 3 palos horizontales y 12 verticales, amarrados con correas de cuero. Dicha puerta se afirma a un poste sur, por medio de dos cordeles de lana de llamo.

Corrales secundarios. Poseen forma rectangular, tamaño pequeñito y se ubican a escasos metros al sur del corral principal. En uno se guardan los burros y en el segundo las crías de ovejas y cabras.

Horno. A unos metros al este de la cocina, se encuentra el horno de barro que nunca pudo utilizarse por fallas en su construcción.

Repostero para burros. Consiste en un simple techo de zinc, con salientes y repisas donde deposita los aperos, monturas, etc.

\section{Campos de cultivo (Figura 2)}

Consisten en grandes campos rectangulares delimitados por muros de piedra de $55 \mathrm{~cm}$ de ancho y $1.10 \mathrm{~m}$ de alto aproximadamente. En su construcción se ha utilizado la técnica de "pirca seca" de la siguiente manera:

En las primeras cuatro líneas inferiores se han colocado en forma horizontal piedras de $30 \mathrm{~cm}$ de ancho formando una doble pared. En las dos líneas siguientes el tamaño de las mismas disminuye a 10 o $15 \mathrm{~cm}$. A continuación se ha depositado una capa de rica-rica (Verbena orígenes Pbil. Verbenaceae) seca, cuya función será la de impedir la entrada de animales al sector. Finalmente una última línea de piedras puestas horizontalmente, sobre las ramas del arbusto para evitar que sean arrastradas por el viento.

Sistema de regadío. El canal de regadío, excavado en la ladera de los cerros, trae el agua del río Puripica. Posee dicho canal $90 \mathrm{~cm}$ de ancho y $25 \mathrm{~cm}$ de profundidad y un muro de piedra y barro evita que el agua se derrame. Desagua en el río Puritama, y para la alimentación de los campos se desvía el líquido por medio del uso de compuertas.

Compuertas. Consisten en una pequeña abertura $(90 \mathrm{~cm})$ cuya base posee tres lajas y su borde dos rodados ovoidales colocados en forma vertical, que permiten poner o sacar una tranca de madera. 
El agua desciende por gravedad hasta llegar al muro exterior del campo, atravesándolo por un boquete de forma rectangular de $42 \mathrm{~cm}$ de ancho y $35 \mathrm{~cm}$ de alto.

Dentro del campo el agua se escurre por acequias paralelas al muro exterior, y por compuertas similares a la descrita va entrando al campo por acequias menores.

\section{Biografía de Juan Vilca}

Juan Vilca nació en Calama en 1905. Hacia 1912 es adoptado y llevado a la localidad de Guatin por sus abuelos. Su abuela provenía de Machuca, mientras que su abuelo de Quetena. Ambos decidieron establecerse en Calama en 1879, como consecuencia de la Guerra del Pacífico.

Años después deciden comprar tierras a Zuroca y Monterola, en Guatin, y trasladarse a la localidad. Las razones de tal decisión se deben al alto precio que a la sazón alcanzaba la piel de chinchilla. Recuerda Vilca que el viaje fue muy penoso porque sólo había una huella maltrecha hasta San Pedro de Atacama y desde allí ni siquiera seguía. Llegados a Guatin construyeron una casa, y la abuela se dedicó a la agricultura, pastoreo y labores artesanales (tejía y trabajaba la greda). Vilca la recuerda como una persona de muchos conocimientos, que sabía rezar y a la que debe gran parte de su educación.

De niño recuerda haber asistido, junto a su abuela, a la fiesta de Guadalupe de Ayquina, que duraba ocho días. Durante aquel lapso, el cura le dio clases y Juan Vilca aprovechó la ocasión para aprender a leer y escribir. No aprendió a contar y por tanto nunca sabe exactamente cuántos animales posee.

Alrededor del año 1935 contrae matrimonio. Recuerda el momento porque decide construir su casa actual, pero nunca menciona a su esposa, de la cual actualmente está separado. El matrimonio tuvo dos hijas y seis varones, uno de los cuales falleció. Todos sus hijos se casaron y emigraron a las urbes cercanas. A pesar de ello, Juan Vilca decide quedarse en Guatin, cuidando su ganado. Desde algunos años, y debido a su avanzada edad, contrata un peón para que lo ayude en sus actividades habituales.

\section{Horario de trabajo}

Creemos que una visión rápida de las labores que realiza un pastor puede indicarse muy claramente con la descripción del horario de trabajo. Este horario varía según las circunstancias, es decir, si tiene un peón que le ayude o si trabaja solo. En Guatin se dan estas dos formas. En el presente trabajo analizamos la vida del pastor y esperamos que en el futuro alguien haga lo mismo, pero esta vez desde el punto de vista del peón. En nuestra estada en Guatin, algunas veces Vilca no contó con ayuda de un peón y, por lo tanto, no pudo mantener el mismo horario de cuando sí tenía ayuda.

Horario con ayuda de un peón: 6.00 se levanta, 7.00 desayuno, 8.00 saca el rebaño a pastar, 9.30 lava y arregla la casa, 10.00 recoge leña, 10.30 cocina, 12.00 almuerzo, 12.30 sigue haciendo cosas en la casa; 17.00 bajada de sol; cocinar la comida y volver al rebaño dentro del corral, 18.00 comida, 19.00 o 20.00 dormir. El horario sin peón es el mismo excepto que se sale a pastar con el rebaño a las 9.30 y se regresa a la puesta del sol. En este sentido no se realizan los trabajos en la casa, en vez de preparar el desayuno, se prepara la comida para todo el día.

\section{Trabajo}

Consideraremos como trabajo principal de Juan Vilca, la actividad de pastoreo y los problemas que éste acarrea: cómo pastar mejor su rebaño. Los otros trabajos son un agregado. La construcción y las dimensiones de la vivienda hacen pensar que el hecho de tener una casa espaciosa es muy importante; sin embargo, si se relaciona con su contenido se observa rápidamente que en la actualidad no es tan relevante; sospechamos que en el pasado su papel ha debido ser mayor. Esto puede explicarse por el hecho de que la agricultura jugaba un papel más importante en la vida diaria, el factor migracional que hace que la casa pierda su valor dentro del sistema de pastoreo y la disminución de las prácticas artesanales. El argumento de Vilca es práctico y simple: las cosas que se hacían anteriormente ahora pueden conseguirse fácilmente desde San Pedro o Calama y entonces no hay necesidad de perder tiempo en su confección. Aunque lo que pueda hacerse en casa resulte más económico y hermoso lo que se adquiere es más práctico y útil. El segundo factor es la estructura social, ya que para tener rebaños y demás útiles de vida diaria hay que tener gente que lo haga. El rebaño es lo que proporciona dinero y, por lo tanto, hay que mantenerlo y conseguir los otros útiles desde el exterior. La falta de personal influye también respecto a la comida, que es un trabajo que no se puede traer desde afuera. En este 
sentido aunque él tiene muchos conocimientos y deseos de preparar variadas comidas, hoy día no se hace más queso, pan o aloja porque todos ellos implican una considerable pérdida de tiempo. Estos se preparan solamente en el día de la fiesta de San Antonio.

El trabajo puede clasificarse en tres categorías: pastoreo, mantención de la casa y la fabricación de materiales para el trabajo y el vivir diario y alimentación.

\section{Pastoreo}

El pastoreo de cabras y ovejas se realiza en dos formas: primero, cada mañana se saca todo el rebaño y se regresa al corral a la puesta del sol. El segundo, ir con el rebaño a una de las estancias (Juan Vilca posee varias, por lo menos tres) y quedarse allá con el rebaño por varias semanas o meses.

Estas dos formas de pastoreo dependen de ciertos factores determinados: 1) cantidad de pasto y áreas verdes alrededor de su vivienda permanente; 2) factores climáticos; 3 ) si tiene un peón y su salud.

Hay que señalar que no cualquier lugar que posee pastos puede ser utilizado. Vilca puede llevar a pastar a sus animales sólo a los lugares que, según la tradición, le han sido asignados a su familia. Las otras áreas pertenecen a otros pastores, su rebaño no puede ocuparlas (Figura 1). Vilca supone que al transgredir la norma podría sucederle algo al rebaño $\mathrm{y}$, en segundo término, equivaldría a un robo, a la apropiación de algo que no le pertenece y "eso no puede hacerse porque es malo y si se hace el mal a los demás puede sucederle lo mismo a uno".

Las áreas donde pasta su rebaño abarcan desde el río Puritama hasta todo lo largo del río Puripica, a ambos lados, pero no más al sur de la quebrada de Chaxas.

Las estancias están ubicadas en los lugares conocidos como "Fundiciones" e "Iglesias". A diferentes alturas del río Puripica; la primera a unos $7 \mathrm{~km}$ y la segunda a unos $15 \mathrm{~km}$ al este de Guatin.

El uso de las tres áreas de pastoreo está determinado, en primer lugar, por su ubicación en nichos ecológicos controlados por los diferentes regímenes pluviales y por la cantidad y variedad de pasto. En segundo lugar, por factores sociales, vale decir, salud del pastor, presencia de peón y cantidad de rebaño. El tercer criterio de selección son los motivos de la crianza del rebaño: para su carne, su leche o su lana.

La ecología de la zona obliga a usar los tres nichos según las estaciones del año. En períodos de lluvia hay bastante pasto a una altura de $3100 \mathrm{~m}$ donde está Guatin mismo y, por lo tanto, no es necesario ir a pastar a una altura mayor. Por consiguiente, en períodos de poca lluvia el pasto se termina y obliga al pastor a moverse a los lugares más altos en su búsqueda. Los meses con mayor cantidad de pasto son generalmente enero, febrero y marzo, cuando llueve en Guatin.

Dijimos también que los motivos de crianza producen cambios en el uso de los nichos ecológicos. $\mathrm{Si}$ el rebaño se cría para venderlo como carne, basta cualquier tipo de pasto y éste se da en cualquier monte. En este caso los alrededores de Guatin son suficientes. Si la crianza, en cambio, fuera para la leche se necesita un tipo especial de pasto llamado basal rosado. Aunque este pasto crece en Guatin, sus áreas propias de crecimiento, donde florece en grandes cantidades, se ubican en lugares de una altitud superior a los $3500 \mathrm{~m}$ y en planicie. Por lo tanto, cuando don Juan piensa aumentar su ganado, decide llevar todo su rebaño a pastar a estos lugares altos, y en particular, a la estancia de Fundiciones.

Si las ovejas se crían por su lana, el rebaño es llevado a una altitud mayor, la estancia de Iglesias, donde el frío denso hace que el pelo de las ovejas aumente considerablemente.

La tropa de llamos, en cambio, permanece en forma permanente en nichos ecológicos de casi 4000 m.snm y sólo se los baja a Guatin cuando se los quiere carnear.

Motivos sociales. Existen dos motivos conectados con el factor ecológico que impulsan a Vilca a usar su estancia de Fundiciones en épocas en que no es necesario hacerlo, por cuanto hay abundante pasto en los alrededores de su casa. El primero es cuando llueve fuerte durante un tiempo prolongado ya que en el corral de Guatin los animales no tienen dónde resguardarse de la lluvia, problema que no se presenta en Fundiciones, ya que el rebaño se protege de la lluvia a lo largo de la quebrada de Puripica con lo cual se evitan enfermedades. 
El segundo motivo para el uso de estancias es el hecho de que Juan Vilca es un hombre de más de 70 años y ya no es como antes. "Los pies no me dan y me comienzo a cansar", por lo tanto no puede salir y volver a Guatin todos los días con su rebaño y necesita un lugar donde haya bastante pasto y pueda dejar a los animales sueltos pastar día y noche. Esto es lo que ocurre generalmente cuando no tiene un peón que lo ayude.

Cuando el ganado se encuentra en Guatin se lleva en forma alternada a pastar a diferentes áreas de pastoreo, con esto se evita que las cabras y ovejas puedan acabar completamente el pasto. Cuando Vilca sale con las ovejas monta en burro y va acompañado por un perro "Pechito". El perro mantiene el rebaño junto corriendo detrás de cada oveja que se salga del grupo. En este caso los animales comen mientras se dirigen hasta el lugar de destino y regresan. Según Vilca, se mide la habilidad de un peón al observar la forma como hace caminar al rebaño. No se le debe dejar caminar demasiado aprisa, como tampoco dejarlo largo tiempo en un mismo lugar ya que pueden terminar el pasto. Por estos motivos es muy difícil, dice el pastor, encontrar un peón que entienda todo el mecanismo, en otras palabras, que conozca las áreas de talaje y el comportamiento que debe observar el rebaño.

Cuando Vilca decide trasladar el rebaño a una de las estancias, este movimiento es de un día entero de preparación. Con este fin lleva consigo dos burros, uno de monta y otro de carga que lleva la comida, el agua y una cama. La comida consiste en fideos, papas, harina, azúcar, té, condimentos. El agua se lleva para evitar tener que bajar a la quebrada para obtenerla del río. Porta, además, fósforos y velas.

\section{Mantención de la vivienda y trabajos manuales}

No cabe duda que la mantención de la vivienda y la fabricación de útiles para el manejo de ésta y para sí mismo constituye el segundo trabajo de Vilca, especialmente cuando tiene un peón que se preocupa de llevar a pastar al rebaño. En temporadas en las que se aleja de casa por largo tiempo, debido a estar sin peón y debe ir a las estancias, la casa comienza a decaer, como pudimos observar en nuestra estada en febrero de 1973. Dos piezas resultaron con el techo dañado. En agosto del mismo año, todo ya estaba arreglado debido a la presencia de Vilca en el lugar y a un peón que le ayudaba en su trabajo.
Fuera del pastoreo realiza tres tipos de trabajos: 1) Mantención de las estructuras: techos, corral, acequias; 2) Fabricación de útiles como ojotas, parchar la ropa y, anteriormente, tejer y hacer cerámica; 3) Cultivo del campo (horticultura).

Para los trabajos mayores como techar o construir, se contratan peones. El material que se usa para estos trabajos se obtiene del lugar. Con esto no queremos decir que se emplee sólo lo que proporciona la naturaleza, como piedras o plantas, sino también lo dejado por los mineros a otras empresas que realizan trabajos en el camino. Don Juan almacena todo lo que pueda servir. Por ejemplo, las ojotas las hace con neumáticos viejos, las herramientas, con trozos de hierro. Lo que no se encuentra se trata de conseguir desde San Pedro de Atacama e inclusive desde Calama por intermedio de amigos o por viajes que él mismo realiza a esos lugares.

Actualmente no se practica el cultivo debido a la escasez de mano de obra. Sin embargo, en febrero de 1973 pudimos comer choclos que Vilca había plantado en sus campos. El trabajo de éstos toma un tiempo y esfuerzo considerables que Vilca no es capaz de aportar más aún teniendo en cuenta que él considera que las ovejas y cabras proporcionan un mayor rendimiento comercial, y por lo tanto, es lógico que las prefiera al cultivo.

Los techos típicos de estas casas de la puna se renuevan, generalmente, cada tres o cuatro años, pero ahora es imposible realizar ese trabajo en forma sistemática y Vilca simplemente parcha las partes que han caído. Tampoco teje ni hace cerámica, puesto que olvidó cómo se realizan esas labores. Lo que no influye mayormente, puesto que actualmente es preferible adquirirlas en los centros urbanos. Prefiere comprar la ropa ya hecha porque se puede parchar y, cuando se rompe, ocurre en algunas partes solamente; en cambio, la hecha a hilo no puede parcharse, inclusive puede romperse entera cuando ocurre algún accidente... Por ello Vilca usa ropa tejida industrialmente, la que está enteramente parchada por él. Piensa que sería mucho mejor tener una mujer que hiciera esto pero, desgraciadamente, no ha encontrado a ninguna que pueda hacerlo en buena forma y barata. Aunque usa zapatos de seguridad de esos que usan los mineros, se dedica a fabricar ojotas para su peón.

Vilca posee los implementos necesarios para preparar el queso y la aloja, trabajo que le agrada, pero debido al tiempo que requiere su preparación, 
prefiere no hacerlo. Sin embargo, nos ha descrito todo su procedimiento, cosa que damos a conocer a continuación.

Para hacer queso hay que preparar el cuajo que se extrae de una tripa de cordero. Se deja durante dos o tres días en una botella de agua. Después de esto se lo mezcla con leche.

La aloja se prepara del algarrobo, que debe conseguir en San Pedro ya que en Guatin no hay. En la despensa tiene un tambor lleno de algarrobo para preparar primero el mingo y otro tambor para hacer la aloja. La aloja se prepara dejando el caldo en un poco de agua caliente en el tambor de madera y después se pasa a otro tambor, se agrega agua mientras se revuelve continuamente, hasta que esté a punto de servirse.

Esa bebida es muy común en toda la zona de San Pedro de Atacama. Se bebe en todas las fiestas principales y también en las menores. Tiene un alto porcentaje de alcohol. Este alcohol se distribuye en las fiestas después de la misa, y es ofrecido a los concurrentes en un jarro de greda por la abuela o por la mujer de mayor edad, en la casa del alférez. Primero se sirve a cada persona pero, una vez que se les ha servido a todos, se dejan los jarros en el suelo para que la gente se sirva cuando quiera, reservando un jarro para los músicos que, a menudo, dejan de tocar para mojarse los labios.

\section{Las comidas}

En el desayuno se sirve té, sopaipillas y restos de carne que quedan del día anterior. El almuerzo y la comida consisten casi siempre en lo mismo: sopa con fideos, ají, aliños, carne de llama, sopaipillas, leche de cabra y té. Aun cuando dijo que no comía de noche, durante nuestra estada en el lugar siempre se sirvió de lo preparado.

Para las fiestas y ocasiones especiales se carnea cordero y se sirven asados. En la fiesta de San Antonio, patrono del lugar, consiguió verduras para la ensalada.

Toda la comida se sirve en forma sencilla, con poco aliño, en forma de sopa, y sólo algunas veces se preparan asados. En general se come mucha carne acompañada de té y sopaipillas que sustituyen al pan. Las sopaipillas deben ser fritas en grasa de llama para que resulten más sabrosas. Vilca prefiere el pan a las sopaipillas pero debido a que el horno que construyera no resultó y él no ha podido encontrar la falla, debe contentarse con las sopaipillas. Su comida predilecta es la fruta en tarros. También le agrada mucho beber, pero bebe cerveza y vino raras veces porque "el trago hace mal y no quiere ir al hoyo todavía".

\section{Vida social}

A pesar de la vida aislada que debe llevar un pastor debido a su actividad, son frecuentes los contactos con otra gente; en primer lugar, y sobre todo, el contacto que mantiene con el peón; en segundo lugar, las relaciones con miembros de su familia; en tercer lugar, las relaciones con comerciantes; en un cuarto lugar entrarían las relaciones con los amigos.

Todas estas relaciones se circunscriben a la zona de Guatin, que es el cruce entre tres lugares: 1) San Pedro de Atacama, el pueblo principal de la zona ubicado a $35 \mathrm{~km}$ al suroeste de Guatin; 2) El Tatio, a $54 \mathrm{~km}$ al noreste donde hay un centro geotérmico $\mathrm{y}$ anteriormente hubo una mina azufrera, el Putana, que terminó de funcionar en el año 1972; 3) El pueblo de Machuca, a $17 \mathrm{~km}$ noroeste de Guatin, con el caserío de Puripite (Turipite) a $7 \mathrm{~km}$. al noroeste de Guatin.

\section{Relaciones con el peón}

El trabajo del peón dentro de la sociedad andina es una intromisión reciente dentro de la estructura. Aunque se puede relacionar el trabajo realizado por el peón con el de otros, como los mitimaes o los yanaconas, el trabajo de éste en la estructura social andina es muy diferente al de aquéllos.

El papel del peón con Vilca es la relación típica de patrón-empleado y tal vez llega a haber una preponderancia despótica del patrón sobre el peón. Durante nuestra estada en Guatin, Vilca tuvo dos peones, uno llamado Concepción Silvestre, nombre que al parecer no era el verdadero sino el que Vilca le dio. $\mathrm{Al}$ inquirir sobre este punto, nos contestó con risas que lo "encontraba un nombre divertido". El segundo peón que tuvo fue una mujer con dos hijos.

El motivo principal por el cual Vilca requiere de la ayuda de un peón es su avanzada edad, lo que le impide llevar a su rebaño a pastar todos los días. Sin embargo, el trabajo del peón no se reduce a esta actividad solamente. El patrón puede exigir de ellos otras tareas cuando está en casa. Así por ejemplo, cuando Vilca está en casa, se sienta y ordena al 
peón que alimente el fuego, que traiga los platos y todo lo que hiciere falta, haciéndolo desempeñar labores domésticas.

La remuneración que percibía un peón por su trabajo ascendía a 20 escudos en 1972 y 30 en 1973, además del alojamiento y comida. Sin embargo, ningún peón permanece con Vilca mucho tiempo, debido al trato humano o simplemente la inestabilidad de esta gente que pasa su vida desplazándose de un lugar a otro.

Ambos motivos se presentan en Guatin. En el caso del primer peón sabemos que su origen es boliviano, que antes de dedicarse al pastoreo trabajaba como ayudante de un llaretero. El segundo caso es aún más significativo. El peón (mujer) es originario de Quillagua ( $21^{\circ} 39$ L.S $69^{\circ} 33$ L.O.), pueblo situado a más de $100 \mathrm{~km}$ al noroeste de San Pedro de Atacama. Esta señora y sus dos hijos se habían radicado en San Pedro hacía ya cinco años; era la familia más pobre del lugar debido a que no encontraba trabajo adecuado. La gente los habían ayudado de variadas formas pero nunca pudieron llegar a tener una posición decente entre los atacameños. Cabe señalar que varias familias provenientes de distintos lugares han llegado a establecerse en San Pedro de Atacama y en uno o dos años logran instalarse adecuadamente, tener su vivienda y conseguir un trabajo para su mantención.

En ambos casos Vilca mantuvo el trato de otorgar alimentación y alojamiento a sus peones, e inclusive con el primero compartió el mismo dormitorio; pero pese a ello no se desarrollaron lazos de amistad ni afecto. El segundo caso fue bastante dramático, ya que al término del contrato Vilca expulsó de su casa a la mujer con sus hijos, los que debieron dormir a la intemperie. Tampoco los dejó cocinar en su cocina, mientras esperaban un medio que los llevara de regreso a San Pedro de Atacama.

A estos hechos se añade la opinión de Vilca, que señala la incapacidad de estos individuos para hacer nada y debido a ello nunca llegan a tener tierras ni rebaños. Agrega además que el trato bueno con ellos los volvería flojos, sin respeto y le restaría validez a su labor.

\section{Relaciones con la familia}

Juan Vilca no vivió solo en Guatin, tuvo una numerosa familia, esposa y ocho hijos. Posteriormente todos emigraron, siguiendo caminos diferentes, pese a ello, de uno u otro modo, mantienen relaciones con él. Frecuentes son con su hijo Julio Tomás, quien vive en San Pedro de Atacama desempeñando varias actividades: llaretero, posee ganado ovino y caprino y un camión fletero con transporte de carga entre San Pedro y Calama. Anteriormente trabajó como conductor de camiones en una mina, de donde obtuvo el camión. Dadas sus actividades, es el hijo que mayores relaciones tiene con su padre, viéndose por consiguiente bastante a menudo. Hace un par de años, Juan Vilca regaló a su hijo Julio Tomás su rebaño de llamos. Sin embargo, debemos destacar el hecho de que las visitas nunca obedecen a razones netamente familiares, sino que siempre existe una necesidad, que depende de los trabajos que esté el hijo realizando. Por otro lado, cuando el padre visita San Pedro de Atacama, nunca aloja en la casa del hijo, sino donde amigos. La explicación aparente sería el hecho de que su hijo vive alejado del centro del pueblo, lo que dificulta su regreso a Guatin. Las amistades de Juan Vilca son clientes, que le han comprado ovejas o cabras, y siempre aprovecha la estada para arreglar sus negocios de compra y venta de objetos y animales.

A veces Vilca viaja hasta Calama donde residen sus hijas, las que frecuentemente retribuyen la visita ayudando al padre en tareas domésticas. Durante su estada en Calama, aprovecha de realizar algunas compras y sus negocios de venta de animales, cueros y lana. Si el tiempo se lo permite visita amigos y bebe una cerveza o taza con vino. En una oportunidad, nos cuenta, fue al cine, pero dado lo encerrado del recinto, como la movilidad de las imágenes, sufrió mareos y tuvo que abandonar la película antes de que ésta terminara. Nunca volvió a repetir la experiencia. Del resto de la familia nunca hace mención, a excepción de su abuela, quien lo llevó a vivir a Guatin y lo educó.

En general, Vilca es un hombre muy conocido en San Pedro de Atacama, y se lo tiene conceptuado como un hombre trabajador y de dinero. La gente recomienda comprar sus corderos, aun cuando cobre más caro. A pesar de su aislamiento siempre está al tanto de lo que sucede en el mundo y no faltan sus indagaciones respecto a los precios de la carne, en las urbes cercanas. Jamás aparece en San Pedro de Atacama durante la celebración de alguna fiesta.

Los contactos con pueblos cercanos tales como Machuca o Turipite son esporádicos y casi nulos. Vilca no estima a la gente que vive en estos lugares 
puesto que opina que son personas "que no saben hacer las cosas como se deben". Ejemplifica su aseveración, señalando que esta gente siempre mantiene sus rebaños de llamos sin introducir otra clase de animales como él hiciera con ovejas y cabras. Además no saben tejer, hacer cerámica, adaptarse a las circunstancias ni hacer negocios. Mantiene un contacto regular con los camiones y camionetas que van al Tatio y a través de ellos hace sus encargos a San Pedro cuando no puede ir.

En años pasados, la familia Vilca celebraba la fiesta de San Antonio, ofreciendo una abundante comida a los camioneros y gente que concurriera. Para la ocasión, tenía un conjunto de instrumentos especialmente traídos de Bolivia. Durante los dos últimos años no se ha celebrado esta fiesta, porque requiere mucho trabajo y debido a la distancia que lo separa de las urbes más cercanas, la gente no acude.

\section{Vida religiosa}

Su formación religiosa proviene de su abuela. Nunca tuvo clases de religión en forma directa ni contacto con el ambiente católico. La religión que profesa ha sido más bien esporádica, sin embargo manifiesta su fe de dos maneras: en sus expresiones de vida diaria y en una especie de ritual.

Como manifestación externa notamos la construcción de una capilla, en las proximidades de su vivienda. Es costumbre entre los atacameños tener un santuario en casa, siendo éste un cuarto o nicho con un santo. Vilca sobresale en esta manifestación al construir una capilla propia, frente a la cual hay una cruz sobre una piedra.

Otra manifestación que no es general en el departamento de El Loa, es la construcción de una cruz sobre el cerro. Esta costumbre es universal pero no en este departamento. El motivo que llevó a Vilca a construirla fue el hecho de que "hubo un tiempo en que existieron grandes remolinos de viento que hicieron que las construcciones que había pegadas al cerro casi se vinieran abajo y por lo tanto existía un mal en el lugar". La solución para expulsar este "mal" entre los atacameños católicos, es la bendición con agua bendita del lugar, realizada por un sacerdote católico. Apenas terminada la construcción del pedestal y de la cruz se buscó al cura de San Pedro para que los bendijera, hecho que repitió el sacerdote tres veces y después de esto, los remolinos desaparecieron.
La fiesta de San Antonio es la expresión máxima de su fe. El escogió a San Antonio como patrono de Guatin, porque la única estatua que pudo conseguir para su capilla fue la de este santo, la que compró a gentes del ayllu de Vilama. Fue hecha en Bolivia, es de greda pintada y está colocada en un nicho de madera con puertas que se abren y cierran. Hoy día no se las puede adquirir porque ya no viene gente de Bolivia como antes. La elección de San Antonio no tiene nada que ver con los motivos hagiográficos del santo, como es usual cuando se escoge patronos de lugares es, en síntesis, un hecho mera y sencillamente accidental.

En tiempos pasados el cura de San Pedro celebraba la fiesta de San Antonio en la localidad de Guatin, pero cuando el pueblo de Camar lo adoptó como su patrono, el sacerdote prefiere dirigirse a Camar a celebrar esta festividad, por cuanto éste es un pueblo más grande que Guatin. Para celebrar la fiesta se ofrece una comida (boda) a todos los que asisten a dicha celebración. Por ello, Vilca tiene especialmente guardada una olla grande, platos y servicio para cocinar y servir la comida a los participantes. También posee todo el conjunto de instrumentos musicales típicos de la zona que él compró en Bolivia, como señalamos anteriormente: siete sicos, flautas de pan, bombo y tambor. La comida de la última boda consistió en cordero asado y ensalada además de aloja. Esta comida en comparación a la ofrecida en otros pueblos en fiestas semejantes es realmente pobre. Creemos, sin embargo, que a su edad no puede realizar todos los esfuerzos para ofrecer una festividad mejor y no es porque no la valore.

La manifestación de su fe se refleja en expresiones diarias como "jarro de Dios" y a cualquier cosa la denomina de Dios. Uno de sus primeros deseos fue aprender a leer para poder leer la Biblia. Este es un hecho curioso. Tal vez es motivado no por el significado mismo de la Biblia sino porque le fue una vez regalada una Biblia.

Su concepto de Dios es el de una persona omnipotente que da todo y de la cual proviene, por lo tanto, El es el que posee todas las cosas y es por eso que llama las cosas de Dios. Es temeroso de Dios quien puede infligirle castigos si no cumple con sus preceptos. Por otra parte, Vilca expresa que no teme a nada, "para qué tener miedo".

Vilca es un gran pensador y sus preguntas son penetrantes. Una de sus interrogantes es qué hace la 
gente que no cree en Dios y si puede existir gente que no crea en El. Para él es inconcebible que alguien no crea en Dios. Además piensa en aquella gente que no posee nada, como por ejemplo, los gitanos, quienes se mueven de un lado a otro, no teniendo entonces una parroquia y aun ni el cementerio donde enterrar a sus muertos, por lo tanto no pueden creer en Dios. Cabe destacar que para los atacameños es una tradición enterrar los muertos en un cementerio donde esté toda la familia. Se pregunta también sobre la religión de los gentiles. Sobre esto nos relató un cuento.

"En San Pedro se encontraron dos estatuas de oro del rey inca. Las tenía un señor en San Pedro pero una vez pasó un argentino y este señor las vendió a él y desde este tiempo no llueve más en San Pedro, porque las estatuas de oro son de Dios y por lo tanto tenían que quedar en San Pedro. Este señor hizo mal y el castigo es el de no tener lluvias".

El cuento puede tener un significado religioso, es decir que Juan Vilca asocia las lluvias como un regalo emanado de Dios, y este regalo debe ser pagado con ofrendas valiosas como son las estatuas de oro. Esta forma coincide con el motivo que le indujo a erigir una cruz en el cerro en señal de ofrecimiento a Dios.

Una forma de religiosidad de Juan Vilca, es su principio ético de lo bueno y lo malo y de lo que es alegría y pena. Dudamos mucho si los conceptos de lo bueno y lo malo, alegría y pena están basados sobre el concepto del dogma católico a través de instrucciones o, simplemente, son conceptos dentro de la ética natural. Está claro que para Juan Vilca lo malo no es la transgresión a una norma establecida sino una relación directa con respecto a la obediencia a Dios, puesto que es Dios -según su propio concepto- quien define en última instancia qué es lo bueno y lo malo. Una ley fundamental y de amplia aplicación es el no pastorear en zonas ocupadas por otros pastores. Aparentemente la transgresión a esta norma no implicaría una sanción de la sociedad de pastores. El respeto a esta ley se cumple porque si se hace mal a los demás el castigo emana de Dios. Por lo tanto, la transgresión a normas es malo para Dios y es El quien castiga.

El sentido de lo malo, para él, se expresa en las personas que no trabajan, que son comerciantes o no creen en Dios. Es de opinión que debe evitarse la compañía de los anteriormente mencionados y que él califica como "gente mala". El nombra frecuentemente gente mala de San Pedro aunque no nos ha dado las razones de esta clasificación, pero aparentemente la "gente mala" es aquella que, según su criterio, son poco capaces de hacer cosas o de ganarse la vida en el mismo tipo de actividad tradicional. Por lo tanto para él son mala gente los de Machuca y los peones, pues son gente que no les gusta gastar nada. Para él, el bueno es aquella persona que sabe hacerse de dinero con su propio sudor y después sabe manejar lo adquirido según las circunstancias. Esto es bueno según él, porque Dios quiere a la gente que trabaja y no a los flojos. Un Dios que sabe de todo no puede gustarle aquella gente que no sabe de nada. Para él, el peón no sabe nada porque hace sólo aquello que le mandan hacer, y muchos de ellos no poseen propiedades. No puede ser entonces que Dios, que tiene todo y sabe todo, le guste esta gente. Este concepto filosófico muy alto y lleno de lógica, naturalmente carece completamente de la visión de Dios como amor y el valor del hombre como persona y, por lo tanto, le falta la encarnación teológica de Cristo. Esto explicaría en parte el tratamiento que le otorga a los peones, descrito anteriormente bajo el título de relaciones sociales.

A pesar de este concepto elevado de lo que él considera bueno y malo, no asocia a Dios con lo bueno, en el sentido que lo bueno es el amor y no simplemente una forma comercial. Sus intereses se centran bastante sobre sí mismo, tal vez a causa de su aislamiento. No podemos decir que Vilca vive con lujo pero lo que él desea tener, puede tenerlo.

Es una costumbre común que el padre, entre los atacameños, sea muy generoso con su núcleo familiar. Esto es en parte una ilustración del concepto de la caridad cristiana, y por otra parte, la costumbre tradicional de los andinos. Pese a ello, Vilca tiene bien escrito en un lugar muy visible lo siguiente: "Juan Vilca a hijos. Campos de Cultivo y Zonas de Pastoreo", en realidad ninguno de sus hijos se quedó con él y lo visitan muy esporádicamente. Este hecho indicaría un sentido poco cristiano de amor mutuo. Con nosotros, Vilca se mostró como una persona agradable pero nunca de generosidad liberal. Todo lo que nos daba hemos tenido que pagarlo a precio superior al de su valor en el mercado, aunque nosotros le hemos regalado varias cosas.

Las ocasiones en las cuales pudimos observar formas de cariño fueron siempre dirigidas a las ovejas y cabras. Para él, estos animales son su vida 
en un doble aspecto, primero el aspecto comercial y luego como compañeros, por lo tanto son obvias sus demostraciones de afecto. Cierta vez, una cabra nació con una pata dislocada. El la cuidaba muy bien dándole leche e inclusive haciéndola dormir en una caja con sacos dentro de su misma pieza. En la mañana la "carneaba", porque según él no se puede dejar a los animales sufrir. Su gran gozo es ver su rebaño. Siempre pide que le saquen fotos en medio de las ovejas y cabras. Incluso una vez quería llevarnos hasta los rebaños de llamas para sacarle fotos.

\section{Alegría y pena}

El motivo de alegría y pena lo introdujimos, porque de las conversaciones de don Juan estas palabras son frecuentemente repetidas. La colocación de estos dos aspectos dentro de un esquema podría deberse al aspecto religioso o teológico o al aspecto filosófico, como en el tema anterior. Ninguno, sin embargo, entra sencillamente en el aspecto estricto de la religión, porque no hay sanciones legislativas de la Iglesia para el que las ejecuta, y tampoco se asocia lo bueno con la alegría ni lo malo con la pena con algún ritual. Si lo consideramos como factor teológico vemos que los motivos no son consecuencia de las fuentes teológicas como ser narraciones de la Biblia, revelación directa o enseñanza magisterial desde la lectura o conversaciones con otras personas como ser el cura o un catequista a otro tipo de educación. Los argumentos de Vilca para emitir juicios sobre las cosas son más bien un análisis filosófico sobre el diario vivir y es sorprendente que al final de su argumentación éstos estén siempre ligados con una imagen de Dios.

En general su filosofía de vida o lo que significa vivir se basa en su concepto de trabajo. Lo que hace a un hombre vivir feliz es el trabajo que realiza. El siempre ríe y hace bromas. Dice que hay que reír para no morir de pena. Desconfía de la gente que no se ríe y que siempre está con cara seria. Para él la gente que no ríe, es mala gente.

Lo que alegra realmente a este hombre es su rebaño y la compañía de un perrito chico con el cual conversa y el que le acompaña a todos los lugares. También dice que una buena mujer, especialmente una bonita, es un buen motivo de alegría pero ahora él está viejo y no debe pensar en ello.

Sostiene que quien no mire a las mujeres es malo y seguramente se muere de pena. En este sentido se refiere directamente a su peón, quien no busca una mujer y por lo tanto es malo. Después de esta afirmación conmina a uno de nosotros, sacerdote, a confirmar su argumentación, no queriendo con ello implicar al matrimonio como algo religioso sino más bien solicitando un raciocinio religioso. No es una obligación dentro de la religión casarse, sin embargo, para él es una obligación natural el vivir con una mujer. Dentro de las comunidades de pastores se ha observado que el matrimonio es deseado porque los hijos constituyen una ayuda al trabajo. En este sentido Vilca fracasó porque nadie de su familia se quedó con él, teniendo que recurrir a la ayuda de peones. Sin embargo, no ha cambiado su concepto sobre la importancia del matrimonio dentro de la vida del hombre. Este hecho nos confirmaría, por lo tanto, que el matrimonio dentro de la comunidad atacameña de pastores tiene un significado mayor que el de una simple fuerza de trabajo. Creemos ver en este caso valores espirituales dentro del matrimonio, los cuales deberán ser mayormente analizados a través del estudio de otros matrimonios de pastores.

El valor de la mujer reside en su fertilidad, su aporte al trabajo doméstico y su ayuda en el pastoreo. Pero dice que no todas las mujeres se desempeñan satisfactoriamente y, por ende, él prefiere no tener si ésta no reúne los requisitos exigidos.

\section{Cultura atacameña}

En los puntos anteriores hemos tratado los aspectos sociales, económicos y filosóficos de la vida de un pastor, que podrían ser típicos en un sentido más amplio de la cultura atacameña. Hasta ahora no tenemos trabajos comparativos que traten de los elementos que caracterizan los parámetros de la cultura atacameña, excepto algunas insinuaciones de trabajos realizados anteriormente y citados en otros informes (Serracino et al. 1975, 1974a, 1974b). En ellos se ha señalado como un rasgo cultural el idioma cunza o atacameño como un factor determinante. Ya Bibar (1558) señala esto. Otros investigadores, Philippi, Vaïsse, Hoyos y Echeverría (1895) y otros, recopilan palabras atacameñas de la zona. Desde ese tiempo no existen mayores datos a excepción de recopilaciones de palabras. Se considera, por lo tanto, que la desaparición completa de la lengua atacameña ocurre en este período (1895). Dado que Juan Vilca nació aproximadamente en este período podría tener conocimiento del idioma o que por lo menos sus padres lo hubiesen conocido. Considerando también el aislamiento del lugar cabe presumir que sería un 
motivo para que el habla castellana hubiese penetrado más tardíamente. Encontramos, sin embargo, que Juan Vilca habla solamente castellano y también su abuela lo hablaba, palabras no castellanas de uso común hay pocas. Preguntamos a don Juan si él conoce palabras atacameñas y nos dio a conocer una docena de ellas, todas referentes a nombres de lugares usados hoy día en la toponimia de sus alrededores. Entregamos acá la lista de nombres sin entrar en mayores detalles:

purifican $=$ agua dulce

turipita $=$ agua cortada $\mathrm{o}$ chica

calar $=$ río helado

cucuter $=$ potreros o sembradíos

licancabur $=$ cerro puntudo

puriponjo $=$ agua hedionda

coriquencal $=$ caracol de río

incapita $=$ inca chico o alojamiento del rey

chaupelona $=$ cerrito del medio

El 90\% de estas palabras proviene de nombres de los alrededores, generalmente usados por todos en San Pedro, pero es muy poca la gente adulta que conoce su significado.

Estas palabras no son aymaras o quechuas, por lo tanto indican que este territorio perteneció a los atacameños. La palabra incapita indica la presencia inca en el lugar, hecho confirmado por la arqueología mediante los restos de cerámica inca y estructuras pequeñas. Esto nos explicaría el conocimiento de Vilca acerca de la historia y que divide en las siguientes etapas: chilena, administración boliviana, inca, gentiles y anterior a los gentiles. Las palabras restantes indican el conocimiento ecológico de la zona porque estas palabras son equivalentes a la descripción geográfica del fenómeno.

Las creencias y los rasgos culturales atacameños pueden extraerse de los cuentos. Lamentablemente nosotros no somos folcloristas y no sabemos hasta qué punto los cuentos que narró don Juan son atacameños o no. Estudios comparativos sobre el tema tampoco tenemos. Los investigadores anteriores a nosotros han recopilado otros cuentos de lugares diferentes a la zona de San Pedro de Atacama (Román 1908, en Susques; Munizaga 1958, en Socaire; Tolosa 1970 y sin fecha). Nosotros recopilamos dos cuentos más aparte del ya explicado en la parte religiosa. La interpretación de estos cuentos necesita un estudio aparte, separando los aspectos lingüísticos y etnográficos, lo que nos apartaría del enfoque del presente trabajo y, por lo tanto, nos limitaremos a su narración.
"Una pastora se fue a los cerros con su rebaño y de pronto una oveja se fue comiendo chañar hasta extraviarse en los cerros. La pastora no pudo encontrarla. La oveja siguió comiendo chañar hasta que éste se acabó. En esa época, como no caía el fruto del arbusto, la oveja decidió agarrar vuelo y remecer el chañar con la cabeza (que en las ovejas y cabras es especialmente dura) hasta que cayeron los chañares al suelo y se los comió. Un día llegó un zorro hambriento y la oveja le preguntó: ¿qué andas haciendo aquí y el zorro contestó: "quiero comer chañar”. La oveja le mostró cómo mover el árbol con la cabeza. El zorro comió y pensó "ahora puedo vivir en cualquier parte" y cuando se le acabó el chañar anduvo por otros lados y agarrando vuelo se fue de cabeza al chañar, se quebró la cabeza y murió".

Este cuento tiene múltiples facetas de interpretación; queremos que los lectores lo relacionen con el concepto de lo bueno y lo malo y el de la alegría y la pena anteriormente señalados en este trabajo. Su valor ecológico es evidente.

La narración del cuento que Vilca atribuye a su abuela nos indicaría la forma de educación que se da a los pastores. Vilca debe su educación a su abuela, sabe escribir y leer pero no contar. Aprendió a escribir cuando viajó con su abuela a Ayquina, a una fiesta, el cura hacía clases de castellano a los niños del lugar según el "Nuevo método del Silabario". El asistió a clases con el permiso de su abuela y así aprendió a escribir algo. Nos confirmó el hecho cuando nos entregó una lista de objetos que le gustaría le trajéramos de Santiago, a nuestro regreso.

\section{Conclusión}

En este trabajo hemos tratado de describir la vida de un pastor en todos sus aspectos dentro del medio ambiente de la precordillera andina, del Desierto de Atacama recopilando los datos acumulados a través de nuestra propia observación. Hemos limitado nuestro análisis al mínimo y sólo entregamos los datos secos para que en futuros trabajos se realice un estudio más completo de la realidad andina del desierto. Creemos que lo señalado, además de tener un justo valor informativo, puede ayudar a la planificación de un estudio integral del sistema pastoril y su significado económico dentro de la estructura de la sociedad andina. Ayudará, además, a interpretar el desarrollo ecológico actual y el modo como funcionaba en el pasado la cultura atacameña. 


\section{REFERENCIAS CITADAS}

ARANDA, X., 1964. San Pedro de Atacama. Elementos diagnósticos para un plan de Desarrollo local. Informaciones Geográficas 11-14: 19-63.

BIBAR, GERONIMO DE, 1966. Crónica y relación copiosa $y$ verdadera de los Reynos de Chile. Fondo José Toribio Medina, Santiago.

BOMAN, E., 1908. Antiquités de la Région Andine de la République Argentine et du desert D’Atacama. Paris.

BOWMAN, I., 1924. Desert trails of Atacama. Special Publication 5. American Geographical Society, Nueva York.

BROWMAN, D., 1974. Pastoral nomadism in the Andes. Current Anthropology 15 (2): 186-196.

CLUSTARD, G., 1973 Ms. Puna zones of the South Central Andes. Paper presented in the symposium of Cultural Adaptations to Mountain Ecosystems. Annual Meeting of the American Anthropological Association, New Orleans, Louisiana.

FLORES OCHOA, J., 1968. Los pastores de Paratía. Una introducción a su estudio. Instituto Indigenista Interamericano. Serie Antropología Social 10, México D.F.

FREZIER, A., 1717. Relation du voyage de la mer du Sud aux côtes du Chile, du Pérou et du Brésél, fait pendant les anées 1712, 1713, 1714. Paris.

IRONS, W. y N. DYSON-HUDSON, 1972. Perspectives on nomadism. E. J. Brill, Leiden.

LE PAIGE, G., 1958. Antiguas culturas atacameñas de la Cordillera Chilena. Revista Universitaria 43 (22): 139-165.

— 1964. El Precerámico en la Cordillera Atacameña y los cementerios del Período Agroalfarero de San Pedro de Atacama. Anales de la Universidad del Norte 3.
_ 1973. El valor arqueológico del Museo San Pedro de Atacama. Estudios Atacameños 1: 9-20.

MOSTNY, G., 1974. Peine, un pueblo atacameño. Instituto de Geografía, Universidad de Chile. Publicación 4.

MUNIZAGA, C., 1958. Relatos populares de Socaire. Centro de Estudios Antropológicos de la Universidad de Chile. Publicación 5: 43-52.

MURRA, J. V., 1965. Herds and herders in the Inca State. En Man, culture and animals: The role of animals in human ecology adjustments. American Association for the Advancement of Science 78: 183-216.

— 1968. An Aymara Kingdom in 1567. Ethnohistory 15 (2): 115-151.

— 1972. El "control vertical” de un máximo de pisos ecológicos en la economía de las sociedades andinas. En Visita de la Provincia de León de Huanuco (1562), por Iñigo Ortiz de Zúñiga. Universidad Hermilio Vardizán, Huanuco.

PHILIPPI, R., 1860. Reise durch die Wuste Atacama. Halle.

SERRACINO, G., R. STEHBERG y G. LIBERMAN, 1973. Proyecto Guatin. Estudios Atacameños 1: 41-42.

— 1974. Informe etnobotánico de Guatin (San Pedro de Atacama). Antropología. Nueva Epoca 1: 55-65.

SERRACINO, G. y R. STEHBERG, 1974. Investigaciones Arqueológicas en Guatin. Estudios Atacameños 2: 7-57.

TOLOSA, B., 1970. Leyendas de tierra adentro. Depto. de El Loa. Provincia de Antofagasta. Edición del autor.

VAÏSE, E., F. HOYOS y A. ECHEVERRIA y REYES, 1895. Glosario de la lengua Atacameña. Anales de la Universidad de Chile 91: 39-56. 